\title{
Ultrasonography is an accurate technique for the diagnosis of gastrointestinal tumors in patients without localizing symptoms
}

\author{
D. Martínez-Ares, P. A. Alonso-Aguirre', J. Souto-Ruzo' ${ }^{1}$ I. Martín-Granizo-Barrenechea, \\ S. Pereira-Bueno, L. Cid-Gómez and J. I. Rodríguez-Prada \\ Service of Digestive Disease. Complejo Hospitalario Xeral-Cíes. Complejo Hospitalario Universitario de Vigo. \\ Pontevedra, Spain. ${ }^{\prime}$ Complejo Hospitalario Universitario Juan Canalejo. A Coruña, Spain
}

\begin{abstract}
Introduction and objectives: this study compared the accuracy of ultrasonography in the diagnosis of gastrointestinal tumors in patients with several degrees of clinical suspicion.

Material and methods: we recruited patients that were suspect for gastrointestinal neoplasia but with no evidence of localizing symptoms (group A), and patients that were suspect for colon cancer (group B) or for gastric cancer (group C). Accuracy in the diagnosis was compared for: gastric cancer in groups $\mathrm{A}$ and $\mathrm{C}$, and for colon cancer in groups $\mathrm{A}$ and $\mathrm{B}$. The comparison was made by using the contingency coefficient, which quantifies coincidence of endoscopic and ultrasonographic diagnoses.

Results: seventy-nine patients were included in group A (48 males), wherein 12 colon and 5 gastric neoplasms were detected. Group B was comprised of 153 patients (78 males) and included 66 patients with colorectal cancer (CCR). Group C contained 58 patients (35 males), 31 of whom were diagnosed with gastric cancer. The accuracy of sonography for diagnosing colon cancer was 95.5\% for group A and $87.5 \%$ for group B. The contingency coefficient for endoscopy vs. ultrasonography was greater for group A: 0.658 than for group B: 0.549. The diagnostic accuracy for gastric cancer was $97.4 \%$ for group A and $86.2 \%$ for group C. The contingency coefficient between endoscopic and ultrasonographic diagnoses was also greater in group A (0.618) than in group C (0.588).

Conclusions: the accuracy of ultrasonography in diagnosing colon and gastric cancer is not lower in patients without localizing symptoms.
\end{abstract}

Key words: Colon cancer. Gastric cancer. Diagnosis. Ultrasonography. Accuracy.

Received: 26-05-09.

Accepted: 10-07-09.

Correspondence: David Martínez Ares. Servicio de Aparato Digestivo. Hospital Xeral-Cíes. C/ Pizarro, 22. 36204 Vigo. Pontevedra, Spain. email: david.martinez.ares@sergas.es
Martínez-Ares D, Alonso Aguirre PA, Souto Ruzo J, MartínGranizo Barrenechea L, Pereira Bueno S, Cid Gómez L, Rodríguez Prada JI. Ultrasonography is an accurate technique for the diagnosis of gastrointestinal tumors in patients without localizing symptoms. Rev Esp Enferm Dig 2009; 101: 773-786.

\section{INTRODUCTION}

Percutaneous abdominal ultrasonography has been proved to be quite precise for diagnosing gastric and colon cancers. These two neoplasms represent more than three fourths of all digestive-tract tumors (1-3), and are located in organs that are easily accessible for ultrasonographic study, in contrast to the esophagus and rectum, which cannot be explored using percutaneous ultrasonography.

Some ultrasonographic features are very suspicious of gut cancer. We should discard the presence of a neoplasm when a thickening of gastric colon walls is observed, especially if such thickening is greater than $10 \mathrm{~mm}$. This fact is manifested by Insko et al. (4), and although specifically referring to gastric cancer, their conclusions can nevertheless be perfectly applied to colon cancer. This study indicates that a wall thickness greater than $10 \mathrm{~mm}$ in the upper gut allows diagnosing a neoplasm with nearly $100 \%$ sensitivity but a specificity of just $42 \%$. For specificity to reach acceptable figures one has to add other data like asymmetric or eccentric thickness, loss of gut wall layers, loss of peristalsis and its compressibility, and contrast enhancement (in the corresponding techniques). When parietal thickening is concentric we observe an image called "pseudo-kidney", because of its similarity to a true kidney's ultrasonographic image.

In any case, the studies that evaluated the accuracy of ultrasonography always included patients that were specifically suspicious of gastric or colon cancer, or in the worst case these would be non-blinded studies where 
patients were already diagnosed using endoscopic or radiological techniques. This fact could greatly impact results obtained. Furthermore, the utility of sonography in such patients seems to be marginal since there is no doubt to date that the golden standard for diagnosing gastric and colorectal neoplasms is endoscopy with biopsy (5-8). Thus, most guidelines and consensus documents recommend that patients with symptoms or alert signs be referred for endoscopy.

The main endpoint of this study was to evaluate how clinical suspicion can determine ultrasonographic accuracy for diagnosing gastric and colonic neoplasms. The results could be highly relevant as it is carried out on patients that are more or less clinically suspect or with nonspecific clinical manifestations, and where ultrasonography, a less invasive technique than endoscopy, could provide a first diagnostic approach. Secondary objectives include the determination of factors that could define differences of diagnostic accuracy (if any) of the technique in several groups of patients.

\section{MATERIALS AND METHODS}

\section{Study design}

The study was designed to blindly and prospectively compare the diagnostic accuracy of ultrasonography for gastrointestinal neoplasm among several groups of patients. Patient consent was obtained for exploration and inclusion in the study since ultrasonography was not the reason why patients had been referred to us.

All ultrasonograms were performed before the endoscopic exploration, a fact that ensures that the operator is blind to the endoscopic diagnosis. Both ultrasonographic and endoscopic explorations were carried out on the same day for outpatients, such that colon ultrasonograms were performed after cleansing with usual cleaning solutions. Inpatients were subject to these two explorations during their hospital stay, but not on the same day; therefore, in most cases ultrasonography was performed on an uncleaned colon. All ultrasonograms were performed by a sole operator using a Toshiba Nemio 10 ultrasonograph (Toshiba Medical Systems Europe, The Nederlands) with a $3.75 \mathrm{MHz}$ convex transducer and a $7.5 \mathrm{MHz}$ linear transducer. A conventional technique was used in all cases, without filling the gastric or colonic cavities with a fluid (hydrogastric or hydrocolonic techniques).

Endoscopy with biopsy is considered the gold standard for the diagnosis of colon and gastric neoplasms since no radiological technique has ever surpassed its diagnostic accuracy and this is the only technique that permits a histological diagnosis. Ultrasonography is considered to be diagnostic for gastric and colon cancer when the abovementioned criteria, taken from Insko et al. (4), are fulfilled (Figs. 1 and 2).

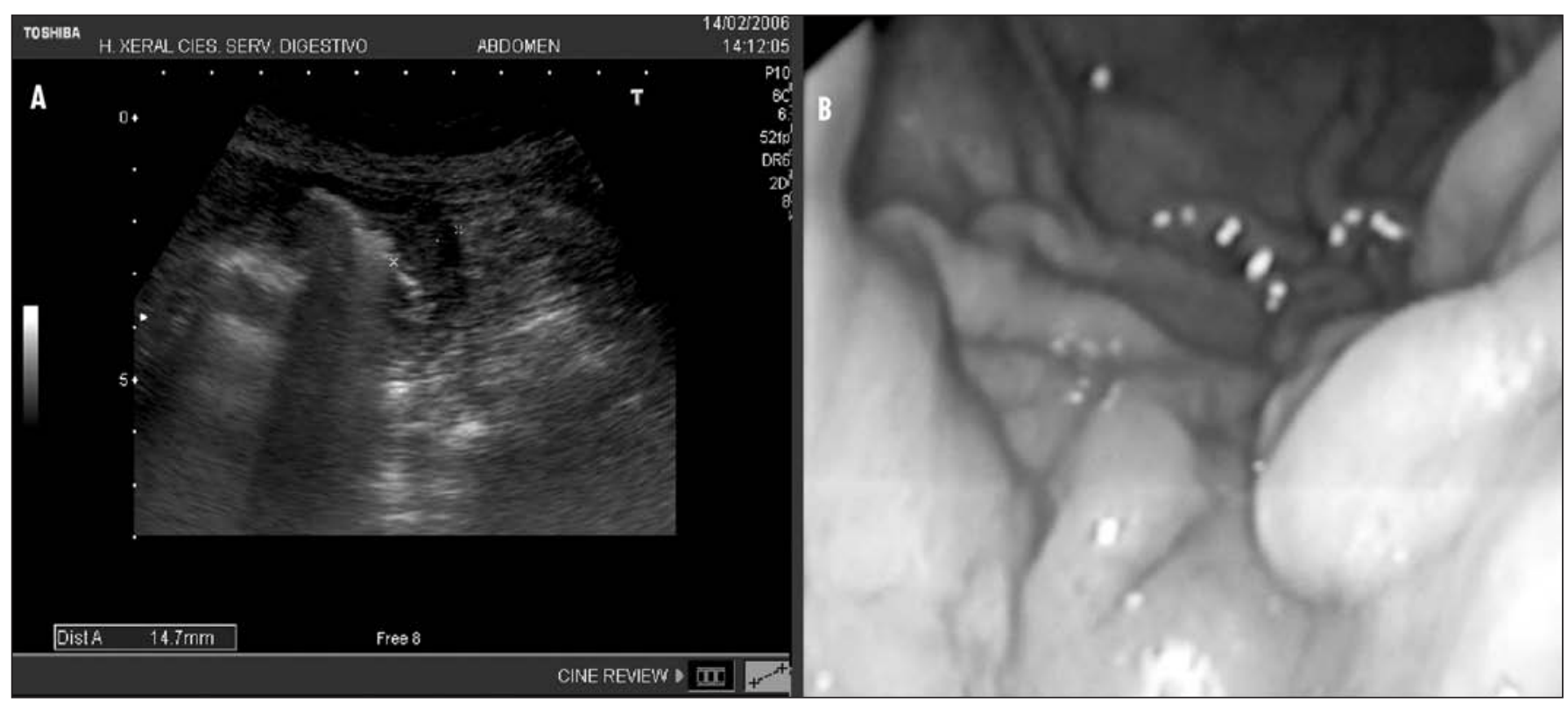

Fig. 1. Here we can verify the correspondence between endoscopic and ultrasonographic images. Ultrasonography (A) shows a 14.7-mm hypoechoic thickening of the wall, with loss of: a) structure in layers; b) compressibility; and c) normal peristaltism. Gastroscopy shows an infiltrative lesion that is slightly ulcerated in some areas, at the level of the major curvature, where biopsies were positive for adenocarcinoma (B).

En esta imagen se comprueba la correspondencia entre las imágenes endoscópicas y ecográficas. En la ecografía abdominal (A), en un corte longitudinal, observamos un engrosamiento hipoecogénico de la pared, de $14,7 \mathrm{~mm}$, con pérdida de la estructura en capas, de la compresibilidad y de la movilidad. La gastroscopia objetiva una lesión de crecimiento infiltrativo, ligeramente ulcerada en algunas zonas, a nivel de la curvadura mayor de antro y con biopsias positivas para adenocarcinoma (B). 


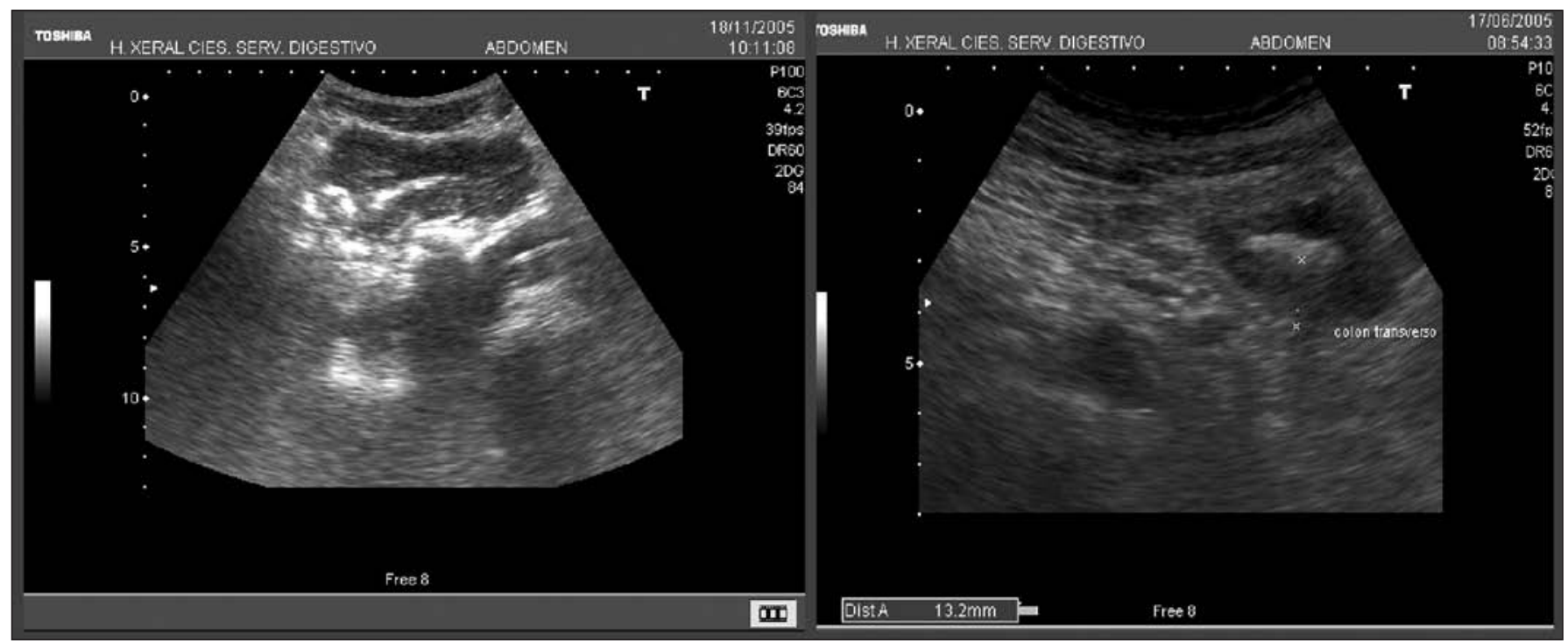

Fig. 2. A "pseudo-kidney" image at the level of the right iliac fossa, which corresponds to a stenosing neoplasm located in the cecum (A), and a "pseudo-kidney" image at the mesogastrium level, towards the left hypochondrium, which corresponds to a stenosing neoplasm of the distal transverse colon (B).

Imagen "en pseudorriñón" o "en diana" a nivel de fosa iliaca derecha, que corresponde con una neoplasia de ciego estenosante (A), e imagen en pseudorriñón a nivel de mesogastrio, hacia hipocondrio izquierdo, que corresponde con una neoplasia estenosante de colon transverso distal (B).

\section{Selection of patients: inclusion and exclusion criteria}

Patients were recruited into the study between August 1, 2004 and December 31, 2005. The only inclusion criterion was that patients had been sent to our Unit for an endoscopic examination to discard gastric or colorectal cancer. Patients were divided up into three groups, with no randomization, using the information provided by clinicians as the sole criterion: group A corresponded to patients suspect of digestive neoplasia with no clear localization; group $B$ was comprised of patients in which the clinician suspected colorectal cancer, and group $C$ contained patients suspect of gastric cancer.

Exclusion criteria were:

- Patients already subjected to endoscopic exploration in the two previous years, which would make a positive diagnosis highly improbable currently.

-Patients with an incomplete endoscopic study. Group A required gastroscopy and colonoscopy, except in cases when one of them was found to be positive.

\section{Statistical analysis}

The parameters assessed were demographic characteristics (age and sex), clinical manifestations and procedure indications, hemoglobin and hematocrit levels, mean cell volume (MCV), ultrasonographic results (normal or pathologic, diagnosis with cancer, and tumor localization), endoscopic findings (type, morphology and localization of lesions), and final diagnosis. By considering endoscopy the gold standard, ultrasonographic diagnoses were classified into true positives and negatives, and false positives and negatives.

The statistical analysis was done using SPSS 12.0 for Windows. Descriptive statistics were performed with the above-mentioned variables. Values for sensitivity, specificity, positive predictive value (PPV), negative predictive value (NPV), and accuracy of ultrasonography for diagnosing colon and gastric cancer were then evaluated. A comparison of results obtained from groups $\mathrm{A}, \mathrm{B}$ and $\mathrm{C}$ was performed by calculating contingency coefficients that relate endoscopic and ultrasonographic diagnostics for each of the three groups of patients.

\section{RESULTS}

Group A contained 79 of all 90 patients that were initially sent to our unit, and they represent $88.8 \%$ of the initial number. Six of these patients were excluded for not completing the endoscopic study, and another 5 were excluded due to a deficient ultrasonographic exploration (in 2 cases related to the stomach and in 3 cases because the colon could not be fully explored). The average time needed for each sonographic examination was $13 \mathrm{~min}$. (range 8-22). Mean age of patients was 69.3 years (range 30 to 89 years). The remaining characteristics of these patients can be seen in table I.

Group B likewise recruited 160 patients that were suspect of colorectal cancer, of which only 153 (95.6\%) were finally included in the analysis. Four patients $(2.5 \%)$ were 
Table I. A summary of socio-demographic characteristics, and of clinical and lab variables for patients in the study. These patients were suspect for digestive neoplasia but did not have any locating symptoms

\begin{tabular}{|c|c|}
\hline Characteristics of patients & Number of patients (\%) \\
\hline $\begin{array}{l}\text { Age } \\
\quad<65 \text { years } \\
>65 \text { years }\end{array}$ & $\begin{array}{l}32.9 \\
67.1\end{array}$ \\
\hline $\begin{array}{l}\text { Sex } \\
\text { Male } \\
\text { Female }\end{array}$ & $\begin{array}{l}60.8 \\
39.2\end{array}$ \\
\hline $\begin{array}{l}\text { Clinical manifestations } \\
\text { Symptomatic anemia } \\
\text { Gastrointestinal bleeding of uncertain origin } \\
\text { Constitutional syndrome } \\
\text { Abdominal pain } \\
\text { Other manifestations }\end{array}$ & $\begin{array}{l}31.6 \\
22.8 \\
17.7 \\
16.5 \\
11.4\end{array}$ \\
\hline $\begin{array}{l}\text { Ultrasonographic findings } \\
\text { Normal ultrasonography } \\
\text { Colonic neoplasia } \\
\text { Gastric neoplasia } \\
\text { Non neoplastic pathology } \\
\text { Chronic pancreatitis } \\
\text { Pancreatic cancer } \\
\text { Uterine cancer } \\
\text { Hypernephroma } \\
\text { Complicated renal cyst }\end{array}$ & $\begin{array}{c}49.4 \\
19 \\
6.3 \\
12.7 \\
2.5 \\
3.8 \\
2.5 \\
2.5 \\
1.3\end{array}$ \\
\hline $\begin{array}{l}\text { Final diagnosis of patients } \\
\text { Colorectal cancer } \\
\text { Gastric cancer } \\
\text { Non-gastrointestinal neoplastic pathology }\end{array}$ & $\begin{array}{l}15.2 \\
6.3 \\
8.9\end{array}$ \\
\hline $\begin{array}{l}\text { Hematocrit value (\%) } \\
\quad<25 \\
25-35 \\
>35\end{array}$ & $\begin{array}{c}26.6 \\
38 \\
35.4\end{array}$ \\
\hline $\begin{array}{l}\text { Mean cell volume }(\mathrm{MCV})(f L) \\
\quad<78 \\
\quad>78\end{array}$ & $\begin{array}{l}29.1 \\
70.9\end{array}$ \\
\hline $\begin{array}{l}\text { Hemoglobin }(\mathrm{g} / \mathrm{dl}) \\
\quad<8 \\
\quad 8-11 \\
>11\end{array}$ & $\begin{array}{l}25.3 \\
31.6 \\
43.1\end{array}$ \\
\hline
\end{tabular}

excluded due to absence of a complete colonoscopy while another 3 patients $(1.8 \%)$ were excluded because ultrasonography was unable to satisfactorily study the colon. Average time needed to study the colon was 8 minutes (range 4-10). Average age of patients was 66.5 years (range 22 to 89 years). Table II shows the remaining clinical-laboratory variables for patients in this group.

Group C initially contained 62 patients suspect of gastric cancer, of which 2 (3.2\%) were excluded for not undergoing gastroscopy while another $2(3.2 \%)$ patients were excluded because ultrasonography was unable to reliably discard a gastric neoplasm. The sonographic exploration of the stomach took on average 5 minutes to per-
Table II. Demographic variables, lab parameters, and clinical manifestations of patients included in the clinically suspect group for colorectal carcinoma

\begin{tabular}{|c|c|}
\hline Characteristics of patients & Number of patients (\%) \\
\hline $\begin{array}{l}\text { Age } \\
\qquad 65 \text { years } \\
\quad>65 \text { years }\end{array}$ & $\begin{array}{l}37.9 \\
62.1\end{array}$ \\
\hline $\begin{array}{l}\text { Sex } \\
\quad \text { Male } \\
\text { Female }\end{array}$ & $\begin{array}{l}51 \\
49\end{array}$ \\
\hline $\begin{array}{l}\text { Clinical manifestations } \\
\text { Lower digestive hemorrhage } \\
\text { Alteration of normal bowel movements } \\
\text { Abdominal pain } \\
\text { Symptomatic anemia } \\
\text { Constitutional syndrome } \\
\text { Other manifestations }\end{array}$ & $\begin{array}{c}30.1 \\
26.1 \\
12.4 \\
7.2 \\
8.5 \\
15.6\end{array}$ \\
\hline $\begin{array}{l}\text { Ultrasonographic findings } \\
\text { Normal } \\
\text { Colon cancer } \\
\text { Non neoplastic pathology }\end{array}$ & $\begin{array}{l}41.8 \\
45.8 \\
12.4\end{array}$ \\
\hline $\begin{array}{l}\text { Final diagnosis of patients } \\
\text { Colon cancer } \\
\text { Benign or null pathology }\end{array}$ & $\begin{array}{l}43.1 \\
56.6\end{array}$ \\
\hline $\begin{array}{l}\text { Hematocrit value (\%) } \\
\quad<25 \\
25-35 \\
>35\end{array}$ & $\begin{array}{c}8.5 \\
32 \\
59.5\end{array}$ \\
\hline $\begin{array}{l}\text { Mean cell volume (MCV) (fL) } \\
\quad<78 \\
\quad>78\end{array}$ & $\begin{array}{l}15.7 \\
84.3\end{array}$ \\
\hline $\begin{array}{l}\text { Hemoglobin }(\mathrm{g} / \mathrm{dl}) \\
\quad<8 \\
\quad 8-11 \\
>11\end{array}$ & $\begin{array}{c}9.2 \\
22.2 \\
68.6\end{array}$ \\
\hline
\end{tabular}

form (range 3 to 7). Mean age for the 58 patients included in the study was 67.4 years (range 23 to 88 ). Table III shows the remainder of data for this group of patients.

In group A ultrasonography was pathologic in 40 cases (50.6\%). However, images were compatible with colon cancer in just 15 cases (19\%) and with gastric cancer in $5(6.3 \%)$ cases. Ultrasonography furthermore enabled a diagnosis of neoplasms that were unrelated to the digestive tract in 7 patients $(8.9 \%$ ), and included 3 cases of pancreatic cancer, 2 uterine neoplasias and 2 hypernephromas. The 12 colonic neoplasms detected through endoscopy were identified by the ultrasonographist (true positives), who registered three false positives. In the remaining patients ultrasonography discarded the presence of colon cancer (true negatives) successfully, without any false negative results. Thus we can deduce that ultrasonography has $100 \%$ sensitivity, $94.5 \%$ specificity, $80 \%$ PPV, $100 \%$ NPV, and an accuracy of $95.5 \%$ in diagnosing CRC (Table IV). 
Table III. A summary of demographic variables, and of lab parameters and clinical manifestations of patients sent to us for suspected gastric neoplasia.

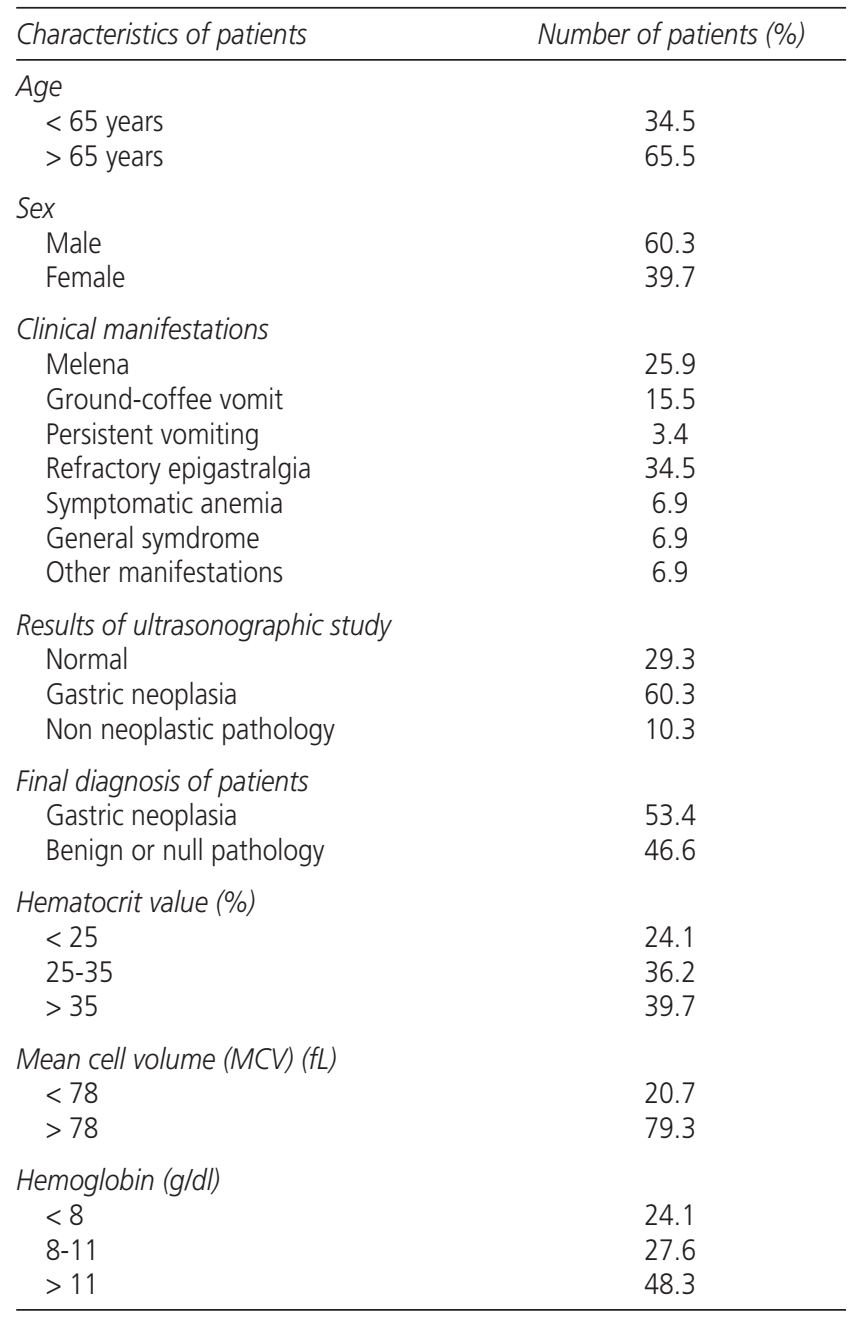

Table IV. A summary of ultrasonography study results for colon cancer diagnosis in each of the group of patients in the study

\begin{tabular}{lcc}
\hline Variable & $\begin{array}{c}\text { Group A with } \\
\text { colorectal cancer }\end{array}$ & $\begin{array}{c}\text { Group B (suspect for } \\
\text { colorectal carcinoma) }\end{array}$ \\
\hline Sensitivity & 100 & 94.8 \\
Specificity & 94.5 & 82.7 \\
PPL & 80 & 78.5 \\
NPL & 100 & 96 \\
Precision & 95.5 & 87.5 \\
\hline
\end{tabular}

A comparison between ultrasonographic and endoscopic diagnosis for gastric cancer in the same group of patients helps us classify ultrasonographic findings as 4 true positives, 1 false negative, 1 false positive, and 73 true negative results, thereby obtaining $80 \%$ sensitivity, 98.6\% specificity, $80 \%$ PPV, $98.6 \%$ NPV, and an accuracy of $97.4 \%$ (Table V).
Table V. A summary of ultrasonographic results for gastric cancer diagnosis in each group of patients in the study

\begin{tabular}{lcc}
\hline Variable & $\begin{array}{c}\text { Group A with } \\
\text { gastric cancer }\end{array}$ & $\begin{array}{c}\text { Group C (suspect for } \\
\text { gastric cancer) }\end{array}$ \\
\hline Sensitivity & 80 & 93.5 \\
Specificity & 98.6 & 77.7 \\
PPL & 80 & 82.8 \\
NPL & 98.6 & 91.3 \\
Precision & 97.4 & 86.2 \\
\hline
\end{tabular}

In group B, ultrasonography was pathological in 89 cases $(58.2 \%)$; however, an ultrasonographic diagnosis of colon cancer was pronounced for just 70 (45.8\%) patients. Diagnosis was confirmed through endoscopy (true positives) in 55 patients, while 15 cases were false positives. On the other hand, 72 ultrasonographic diagnoses were considered to be true negatives and 11 as false negatives. From these data we get a sensitivity of $83.3 \%$, a specificity of $82.7 \%$, a PPV of $78.5 \%$, a NPV of $86.7 \%$, and an accuracy of $83 \%$. If we exclude the 8 rectal lesions (expected false negatives, since the rectal ampulla could not be examined with ultrasonography), then the figures for sensitivity, specificity, PPV and NPV for ultrasonography increase to $94.8,82.7,78.5$ and $96 \%$, respectively. Accuracy would be $87.5 \%$ (Table IV).

In group $\mathrm{C}$, ultrasonography shows pathology in 41 cases $(70.7 \%)$, and was positive for gastric cancer in 35 cases $(60.3 \%)$. Findings were confirmed through endoscopy (true positives) in 29 patients, with just 6 false positives observed. On the other hand, ultrasonography successfully discarded the presence of neoplasms (true negatives) in 21 patients, with just 2 false negatives observed. Therefore, the sensitivity obtained becomes $93.5 \%$, specificity $77.7 \%$, PPV $82.8 \%$, NPV $91.3 \%$, and accuracy stands at $86.2 \%$ (Table V).

Accuracy shown by ultrasonography for colon cancer diagnosis in group A (patients without localizing symptoms) reaches $95.5 \%$, which is greater than that obtained for group B (patients sent to our unit for colon cancer suspicion), where accuracy was $87.5 \%$. This finding can be checked by calculating contingency coefficients that relate ultrasonography and endoscopy diagnostics. The value of such coefficient is 0.658 ( $\mathrm{p}<0.0001)$ in group A and $0.549(\mathrm{p}<0.0001)$ in group B. Likewise, ultrasonographic precision for gastric cancer diagnosis is greater in group A patients (97.4\%) than in patients suspect specifically to have gastric cancer $(86.2 \%)$ (Table V). This difference is reflected by contingency coefficients: $0.618(\mathrm{p}$ $<0.0001)$ for group A and $0.588(\mathrm{p}<0.0001)$ for group $\mathrm{C}$, for endoscopic and ultrasonographic diagnoses.

One datum, which although not included within the scope of this study would certainly be relevant, is that of colon tumor localization (Fig. 3). Groups A and B include a sum total of 78 colorectal neoplasms, of which $10.2 \%$ are rectal, $44.9 \%$ were localized in the sigma, 


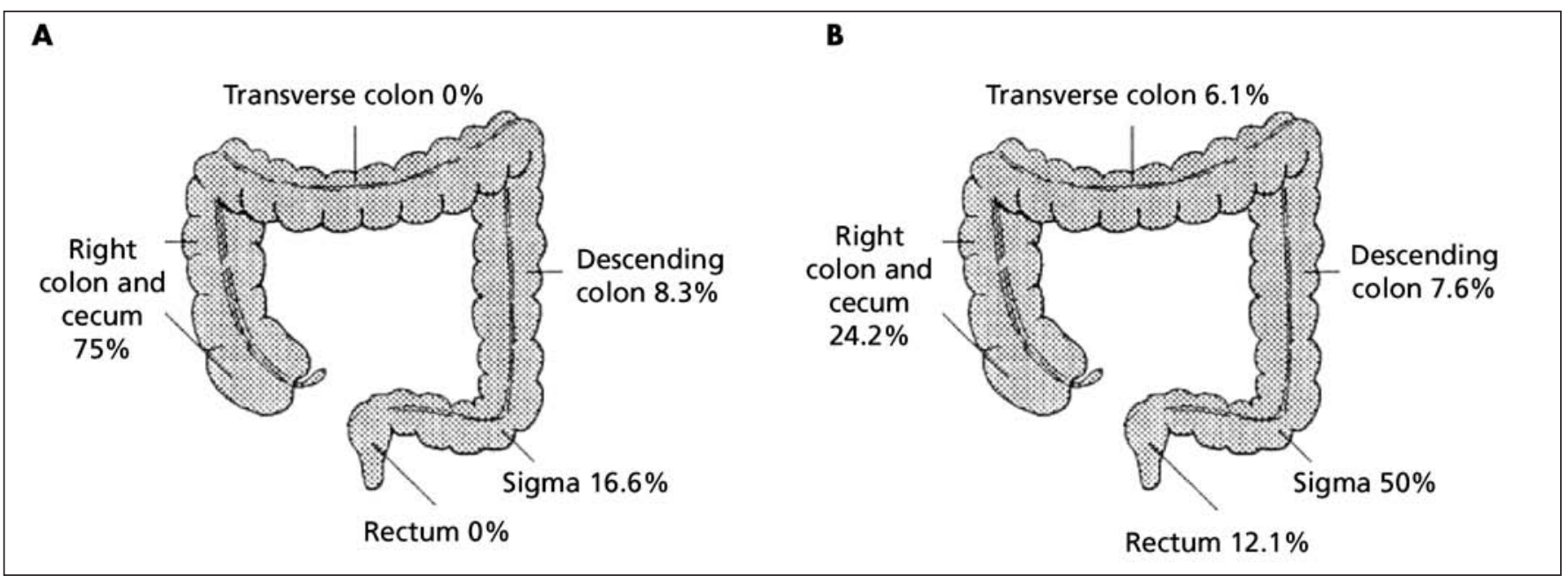

Fig. 3. A schematic representation of colorectal cancer location in patients included in our study both for group $A(A)$ and for group $B(B)$. Esquema representativo de la localización de los tumores de colon que presentaban los pacientes incluidos en nuestro estudio tanto en el $A$ (A) como en el grupo B (B).

$7.7 \%$ in left colon, $5.1 \%$ in the transversal colon, and $32 \%$ in the right colon. Upon exclusively analyzing patients from group $\mathrm{B}$, we find tumor distribution to be quite similar: $12.1 \%$ rectal tumors, $50 \%$ located in the sigma, $7.6 \%$ in the left colon, $6.1 \%$ in the transversal colon, and $24.2 \%$ in the right colon. However, in patients from group A, $75 \%$ of tumors were located in the right colon, $16.6 \%$ in the sigma, and $8.3 \%$ in the left colon. No rectal lesions were observed. In the case of cancer patients with no symptoms to suggest a colonic origin, it was observed that tumors were located in the right colon with a significantly higher frequency, where odds ratio (OR) reaches 8.64 (95\% CI 2.09-35.71) ( $\mathrm{p}=0.001)$; however, when such symptoms are present, neoplasms tend to be located in the recto-sigmoid, where OR is 3.63 $(95 \%$ CI 1.01-13.07) $(\mathrm{p}=0.005)$.

\section{DISCUSSION}

Diagnostic precision figures obtained by ultrasonography in this study, both for gastric cancer and colon cancer diagnosis, and for patients either less or more suspect for this pathology, were found to be quite similar to some published results and clearly higher than those from other studies in the literature. Results are also quite similar to those obtained by our group in a previous study (9). There are very few studies that we can compare our findings with, and some of these are quite poor. On the other hand, none of the studies have performed the same comparison as in ours. This we feel is the greatest contribution of our work because ultrasonography would not have a relevant role in colon and gastric cancer diagnoses if these cancers were already suspected prior to performing an ultrasonogram. However, ultrasonography can play an important role when selecting endoscopy as first exploration in patients suspect of digestive cancer but no clues to decide on the most probable location.

The first study that evaluated the usefulness of ultrasonography in diagnosing colon cancer was that by Rutgeerts et al. (10), who obtained a sensitivity of only $50 \%$. These low sensitivity figures are quite striking, bearing in mind that this was an unblinded study. However, the sensitivity obtained for right colon cancers was $95 \%$, which we feel is quite important as we shall explain later. Uchida et al. (11) in an adequately designed study but with only 53 patients also obtained a sensitivity of just $52 \%$, which rose to $75 \%$ after a second ultrasonographic examination of the patients diagnosed. Richardson et al. (12), in a recent study, albeit with the same methodological defects, obtained sensitivity and overall accuracy figures of 96 and $91 \%$, respectively, which are very similar to our results, but with a specificity of just $67 \%$. Loftus et al. (13) did a blind and prospective comparison of abdominal ultrasonography and $\mathrm{CT}$, with colonoscopy as the gold standard. They got a sensitivity and specificity of $100 \%$ for ultrasonography and a sensitivity of $100 \%$ and a specificity of $84 \%$ for CT, although we should bear in mind that these series only contained 7 colon cancer patients. Lim et al. (14) and Grunshaw et al. (15) studied patients with known intestinal obstruction, where tumors were one of the most frequent causes. They got sensitivity figures of 75 and $80 \%$, respectively. Lastly, Shirahama et al. (16) obtained a PPV of $90 \%$, this being the only evaluation parameter that the study designs permitted.

Some authors feel that conventional ultrasonography does not provide a reliable diagnosis of colon tumors, 
thereby requiring the hydrocolonic technique, although just two studies compared the two modalities, which showed a clear inferiority of conventional ultrasonography $(17,18)$. In studies specifically of hydrocolonic ultrasonography, sensitivity oscillated between 77 and $96.8 \%$ (19-22). These results are nearer our results, both for the group of patients suspect for CRC and the group without localizing symptoms. However, the hydrocolonic technique does seem to be superior, at least when we compare literature results with our own, in the specificity of the technique. The price to pay for a higher PPV, without apparent improvement in NPV, is a greater exploration time and greater patient discomfort in some cases. There are also some vasovagal complications described for some patients (18).

The sensitivity obtained by ultrasonography in the diagnosis of colon cancer is comparable to that of barium enema, which can have certain limitations when evaluating the right colon (23-26). On the other hand, Rutgeerts et al. (10), and Grunshow et al. (15) concluded that ultrasonography sensitivity is greater in this segment of the colon. In our series, $100 \%$ of right colon lesions identified were diagnosed through ultrasonography. According to our study, in patients that do not present with localizing symptoms (group A), neoplasms were located in the right colon with a probability that was 9 times higher (OR 8.64, p = 0.001), and this could be the reason for a greater ultrasonographic diagnostic precision in patients without neoplasia locating symptoms than for patients suspect of CRC. We therefore consider that ultrasonography could be a good diagnostic approach for patients without specific symptoms, in whom right colon lesions are increasingly frequent and where the typical manifestation is ferropenic anemia, arising from unapparent chronic bleeding and scarce digestive symptoms $(27,28)$.

A high accuracy was obtained for gastric cancer both in suspect patients that were referred to us, and in patients with nonspecific clinical manifestations. Our results obtained through the use of conventional techniques are comparable to those obtained by other authors with hydrogastric ultrasonography (with the gastric cavity filled with liquid). In this case, we once again faced the same difficulties described above for CRC when we tried to compare our results with literature results. Few studies evaluate the usefulness of ultrasonography, and few of them are prospective and well designed. Worlicek et al. (29), in an older study, obtained a sensitivity and specificity of 82.4 and $94.9 \%$, respectively, by using hydrogastric ultrasonography. Boyacioglu et al. (30) also used the hydrogastric technique and obtained a sensitivity of just $78 \%$. Tous et al. (31) published a sole comparative study of conventional ultrasonography with hydrogastric ultrasonography. The sensitivities of both the conventional technique $(69 \%)$ and hydrogastric exploration $(75 \%)$ were less than expected, although they obtained a greater specificity (99\%). Segura-Cabral et al. (32) communicated a sensitivity of $87.5 \%$; Quiroz-Moreno et al. (33), in a study of just 20 gastric tumors, mention a sensitivity of 95\%; Lim et al. (34) cited a sensitivity of $84 \%$, and Richter et al. (35), in a study that compared hydrogastric ultrasonography with abdominal CT, that was also performed after filling the bowel with liquid, obtained a sensitivity of $77 \%$ for ultrasonography.

We too obtained a higher diagnostic precision for gastric cancer in patients with nonspecific symptoms. In this case, differences were in all probability due to the limited presence of gastric neoplasms in group A patients, and were highly unlikely to be due to striking facts such as the different locations of tumors in the two groups of patients. This conditions a more discrete NPV but enables to obtain a NPV above $98 \%$. As is well known, both PPV and NPV depend greatly on the prevalence of the disease in the population studied, and such high NPV is what obviously improves global precision figures.

Our main objective has been fulfilled from a general point of view. We were able to show that ultrasonography is an accurate technique for gastric and colon neoplasm in patients with no suggestive symptoms of neoplasia location. In these patients, ultrasonography is at least as sensitive as in patients suspect of gastric or colon cancer. On the other hand, in this group of patients with nonspecific symptoms that were initially sent to us for endoscopic exploration, ultrasonography has enabled a diagnosis with a considerable frequency for significant, neoplastic and non-neoplastic conditions unrelated to the digestive tract. This leads to think that ultrasonography can be a useful tool for selecting endoscopic exploration in patients that need discarding digestive neoplasms but in which we do not have any clues regarding whether a gastric or colon neoplasia should be first discarded. Ultrasonography can further avoid all endoscopic explorations in cases where diagnoses require other diagnostic techniques, as in the case of patients with pancreatic, uterine, or renal neoplasms.

\section{REFERENCES}

1. Parkin DM, Pisani P, Ferlay J. Global cancer statistics. CA Cancer J Clin 1999; 49: 33-64.

2. Greenlee RT, Murray T, Bolden S, Wingo PA. Cancer statistics, 2000. CA Cancer J Clin 2000; 50: 7-33.

3. Shibuya K, Mathers CD, Boschi-Pinto C, Lopez AD, Murray CJ. Global and regional estimates of cancer mortality and incidence by site: II. Results for the global burden of disease 2000. BMC Cancer 2002; $2: 37$.

4. Insko EK, Levine MS, Birnbaum BA, Jacobs JE. Benign and malignant lesions of the stomach: evaluation of CT criteria for differentiation. Radiology 2003; 228: 166-71.

5. Dafnis G, Blomqvist P, Granath F, Pahlman L, Ekbom A. Colorectal cancer detection by colonoscopy in a Swedish county, 1979-95. Scand J Gastroenterol 2003; 38: 1059-67.

6. Smith GA, O'Dwyer PJ. Sensitivity of double contrast barium enema and colonoscopy for the detection of colorectal neoplasms. Surg Endosc 2001; 15: 649-52.

7. Triantafillidis JK, Cheracakis P. Diagnostic evaluation of patients with early gastric cancer-a literature review. Hepatogastroenterology 2004; 51: 618-24. 
8. Hosokawa O, Tsuda S, Kidani E, Watanabe K, Tanigawa Y, Shirasaki S, et al. Diagnosis of gastric cancer up to three years after negative upper gastrointestinal endoscopy. Endoscopy 1998; 30: 669-74.

9. Martinez-Ares D, Martin-Granizo Barrenechea I, Souto-Ruzo J, Yanez Lopez J, Pallares Peral A, Vazquez-Iglesias JL. The value of abdominal ultrasound in the diagnosis of colon cancer. Rev Esp Enferm Dig 2005; 97: 877-86.

10. Rutgeerts LJ, Verbanck JJ, Crape AW, Buyse BM, Ghillebert GL. Detection of colorectal cancer by routine ultrasound. J Belge Radiol 1991; 74: 11-3.

11. Uchida M, Sakoda J, Fujitoh H, Kumabe T, Oshibuchi M, Hayabuchi $\mathrm{N}$, et al. Reappraisal of the clinical usefulness of transabdominal ultrasonography for advanced colon cancer-a study of tumor detection. Nippon Igaku Hoshasen Gakkai Zasshi 1993; 53: 261-5.

12. Richardson NG, Heriot AG, Kumar D, Joseph AE. Abdominal ultrasonography in the diagnosis of colonic cancer. Br J Surg 1998; 85: 530-3.

13. Loftus WK, Metreweli C, Sung JJY, Yang WT, Leung VKS, Set PAK. Ultrasound, CT and colonoscopy of colonic cancer. B J Radiol 1999; 72: 144-8.

14. Lim JH, Ko YT, Lee DH, Lee HW, Lim JW. Determining the site and causes of colonic obstruction with sonography. AJR Am J Roentgenol 1994; 163: 1113-7.

15. Grunshaw ND, Renwick IG, Scarisbrick G, Nasmyth DG. Prospective evaluation of ultrasound in distal ileal and colonic obstruction. Clin Radiol 2000; 55: 356-62.

16. Shirahama M, Koga T, Ishibashi H, Uchida S, Ohta Y. Sonographic features of colon carcinoma seen with high-frequency transabdominal ultrasound. J Clin Ultrasound 1994; 22: 359-65.

17. Limberg B. Diagnosis and staging of colonic tumors by conventional abdominal sonography as compared with hydrocolonic sonography. N Engl J Med 1992; 327: 65-9.

18. Hernández-Socorro CR, Guerra C, Hernández-Romero J, Rey A, Lopez-Facal P, Alvarez-Santullano V. Colorectal carcinomas: diagnosis and preoperative staging by hydrocolonic sonography. Surgery 1995; 117: 609-15.

19. Segura JM, Molina E, Herrera A, Berges MA, Erdozain JC, Arjonilla A, et al. Hidrocolonic ultrasonography in the detection of tumoral processes in the inferior gastrointestinal tract. Rev Esp Enferm Dig 1998; 90: 779-87.

20. Walter DF, Govil S, William RR, Bhargava N, Chandy G. Colonic sonography: preliminary observations. Clin Radiol 1993; 47: 200-4.

21. Dux M, Richter GM, Roeren T, Heuschen U, Kauffmann GW. Gas- trointestinal imaging with hydrosonography and hydro-CT. Rofo 1996; 164: 359-67.

22. Candia C, Ciacci V, Di Segni R, Santini E. Hydrocolonic sonography in the study of colonic diseases. Comparison with double-contrast enema. Radiol Med (Torino) 1995; 89: 258-63.

23. Bolin S, Franzen L, Nilsson E, Sjodahl R. Carcinoma of the colon and rectum. Tumors missed by radiologic examination in 61 patients. Cancer 1988; 61: 1999-2008.

24. Martinez F, Kondylis P, Reilly J. Limitations of barium enema performed as an adjunct to incomplete colonoscopy. Dis Colon Rectum 2005; 48: 1951-4.

25. Segal R, Khahil A, Leibovitz A, Gil I, Annuar M, Habot B. Barium enema in frail elderly patients. Gerontology 2000; 46: 78-82.

26. Levine MS, Rubesin SE, Laufer I, Herlinger H. Diagnosis of colorectal neoplasms at double-contrast barium enema examination. Radiology 2000; 216: 11-8.

27. Zhang B, Fattah A, Nakama H. Characteristics and survival rate of elderly patients with colorectal cancer detected by immunochemical occult blood screening. Hepatogastroenterology 2000; 47: 414-8.

28. Nakama H, Zhang B, Fattah AS, Zhang X. Colorectal cancer in iron deficiency anemia with a positive result on immunochemical fecal occult blood. Int J Colorectal Dis 2000; 15: 271-4.

29. Worlicek H, Dunz D, Engelhard K. Ultrasonic examination of the wall of the fluid-filled stomach. J Clin Ultrasound 1989; 17: 5-14.

30. Boyacioglu S, Dolar E, Acar Y, Dalay R, Temucin G. Ultrasonographic scoring system: an auxiliary to differential diagnosis of gastric pathologies. J Clin Ultrasound 1993; 21: 97-101.

31. Tous F, Busto M. Assessment of abdominal sonography in the diagnosis of tumors of the gastroduodenal tract. J Clin Ultrasound 1997; 25: 243-7.

32. Segura Cabral JM, Conde Gacho P, Comas Redondo C, Olveira Martin A, Segura Grau A, Erdozain Sosa JC, et al. The usefulness of hydrogastric ultrasonography in the detection of neoplastic lesions of the gastric wall. Gastroenterol Hepatol 1999; 22: 63-6.

33. Quiroz Moreno R, Morales Guzman MI, Cervantes Monroy JA, Rueda Torre G, Diaz Caldelas L. Exactness of transcutaneous sonography in the diagnosis of gastric wall lesions. Rev Gastroenterol Mex 2003; 68: 245-52.

34. Lim JH, Ko YT, Lee DH. Transabdominal US staging of gastric cancer. Abdom Imaging 1994; 19: 527-31.

35. Richter GM, Dux M, Roeren T, Heuschen U, Kauffmann GW. Gastrointestinal diagnosis with hydrosonography and hydro-CT. 1: Stomach carcinoma. Rofo 1996; 164: 281-9. 